\title{
Osteoporotic Verterbal Compression Fractures
}

\author{
Kook Jin Chung \\ Department of Orthopaedic Surgery, Kangnam Sacred Heart Hospital, \\ College of Medicine, Hallym University \\ Korea
}

\section{Introduction}

As the number of old people has been growing, health care of these has been one of major socioeconomic concerns, especially in the developed countries.

Musculoskeletal diseases according to aging process are as much important as medical illness. Based on a report ${ }^{1}$, newly diagnosed people with osteoporosis are estimated to affect 200 million women in the world. Because women has lower peak bone mass than men and lose bone mass rapidly right after menopause as they become older. So, osteoporosis imposes a greater burden on women.

The incidence of all osteoporotic vertebral compression fractures increases with age. ${ }^{2}$ Shortly after menopause, the incidence of wrist fracture begins to increase and continues to do so until of age of 65 , when it plateaus. Vertebral fracture, the most common fracture, occurs earlier after menopause than hip fracture, and continues to rise with age.

Approximately 1.5 million osteoporotic fractures occur in the United States annually, comprised of 250,000 wrist fractures, 250,000 hip fractures, 700,000 vertebral fractures, and 300,000 fractures at other sites. Thus, most common osteoporotic fractures are vertebral fractures. ${ }^{3-7}$

Conventional treatments with bed rest, oral or parenteral analgesics, early ambulation with a brace after relieving symptoms is sufficient to treat osteoporotic vertebral compression factures.

But some patients complain of severe pain that does not respond to these treatments and even show progressive collapse of vertebral bodies and kyphotic deformity with or without neurologic deficits.

Most patients with osteoporotic vertebral compression fractures (OVCFs) well respond to conservative treatments including bed rest, analgesics and immobilization with brace.

But, some of patients complain of uncontrolled persistent chronic pain and progressive collapse of vertebral body, post-traumatic kyphosis with or without neurologic deficits. It is well known that osteoporotic fracture is also associated with significant morbidity and mortality in postmenopausal women. ${ }^{8-12}$ There was an approximate 2-fold increase in risk of death following any clinical fracture, primarily due to a 9-fold increase in mortality 
following vertebral fractures. ${ }^{13}$ In contrast, there was no increase in risk of mortality associated with forearm fracture or fractures at sites other than the spine, wrist, or hip.

These data suggest that clinical fractures, particularly vertebral fractures, are associated with an increased risk of mortality in postmenopausal women. Interestingly, the increased mortality following vertebral fracture is comparable to that caused by hip fractures and associated with severe back pain followed by progressive kyphotic deformity and pulmonary dysfunction and its sequelae.

It should be noted that the mechanism behind increased mortality associated with vertebral fractures remains unclear, but may be related more to underlying health status, and comorbidities rather than the actual fracture itself. ${ }^{14}$ Clinical vertebral fractures may be diagnosed more often in women with generally poorer health, a bias that may also contribute to the relationship between vertebral fracture and mortality.

Even though more aggressive treatment may be needed in these complicated cases followed by osteoporotic vertebral compression fractures with majority of patients are not ideal candidates for surgical treatments especially under general anesthesia.

Vertebroplasty was first introduced by Galibert et al in 1987 for the treatment of vertebral body tumor. ${ }^{15}$ And then it was adopted as a successful treatment of osteoporotic vertebral compression fractures with advantages of rapid pain relief and long-lasting effect over conventional treatments for several decades. But it has limitation in view of restoration of reduced body heights and leakage of Polymethylmethacrlylate during the procedue.

With the aid of newly designed minimally invasive technique, balloon kyphoplsty the collapsed vertebral body has been reduced satisfactorily by an inflatable bone tamp and then polymethylmethacrylate was safely put into cavity made by bone tamp with less pressure than vertebroplasty. Early results of kyphoplasty for the treatment of osteoporotic vertebral compression fractures has provided restoration of collapsed vertebral body height and reduction of kyphosis, sasitified pain relief and sufficient recovery of daily activity.16-19

For those reasons, balloon kyphoplasty has been substituted for vertebroplasty. Thesedays the indication of balloon kyphoplasty has been expanded to include pathological fractures, chronic vertebral fractures and even revision cases. ${ }^{20-22}$

Since the early report described by Garfin et al, bilateral approach using two balloons are usually used to provide en masse reduction for the more efficienct reduction of kyphosis. To the author's knowledge, many surgeons preferred to use bilateral technique. There has been just one study reporting on the clinical result using unilateral kyphoplasty by Boszczyk et $\mathrm{al}^{23}$ using transcostovertebral approach in mid and high thoracic area. But as well known, osteoporotic verterbral compression fractures usually occurs most commonly in the thoracolumbar junction especially in $12^{\text {th }}$ thoracic and $1^{\text {st }}$ lumbar vertebra. 20,24

I already reported that the results of comparative study of balloon kyphoplasty with unilateral versus bilateral and unilateral approach in thoracolumbar junction. ${ }^{25}$

Unlike bilateral approach, bone tamp needs to be advanced more to the midline on the anteroposterior view for the purpose of more central placement of balloon in thoracoulumbar junction. (Fig 1,2) According to the result, pain relief was not statistically different but postoperative reduction of fracture and loss of reduction was better in bilateral 
approach. Although pain score for the two techniques provided same effect, bilateral approach of balloon kyphoplasty can achieve reduction of kyphotic deformity due to an osteoporotic vertebral compression fractures to gain good sagittal alignment. (Fig 3-A,B) fractures occurred in mid and high thoracic spine and cases not requiring so much reduction for restoration of kyphosis. ${ }^{24,25}$

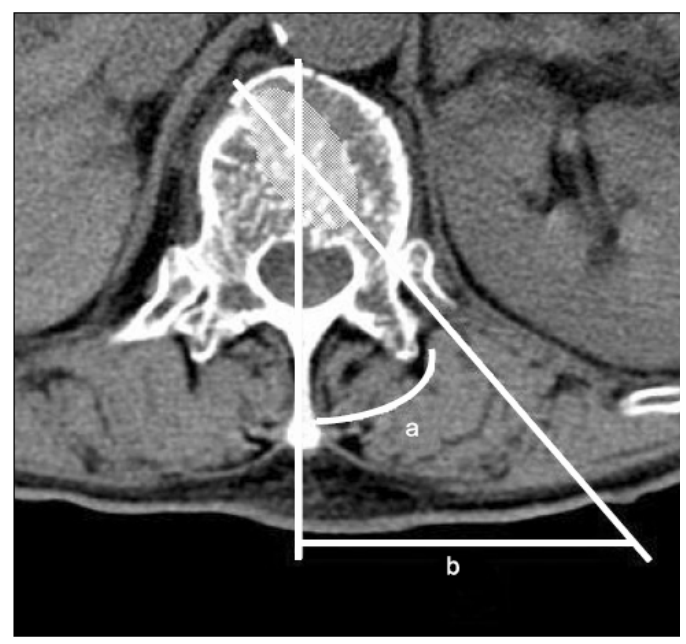

Fig. 1. Balloon kyphoplasty using unilateral Approach. The angle (a) formed by the two lines connecting the most ventral portion of the vertebral body and the spinous process and the line is placing balloon in the middle of the vertebral body, distance (b) between the two points where these two lines contacted the body surface.

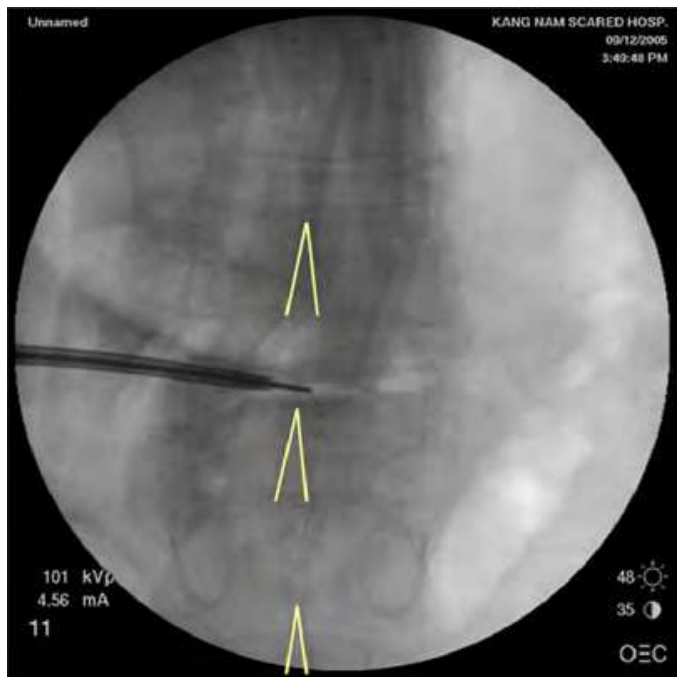

Fig. 2. Bone tamp is advanced to the midline on the anteroposterior view under the C-arm image intensifier. 


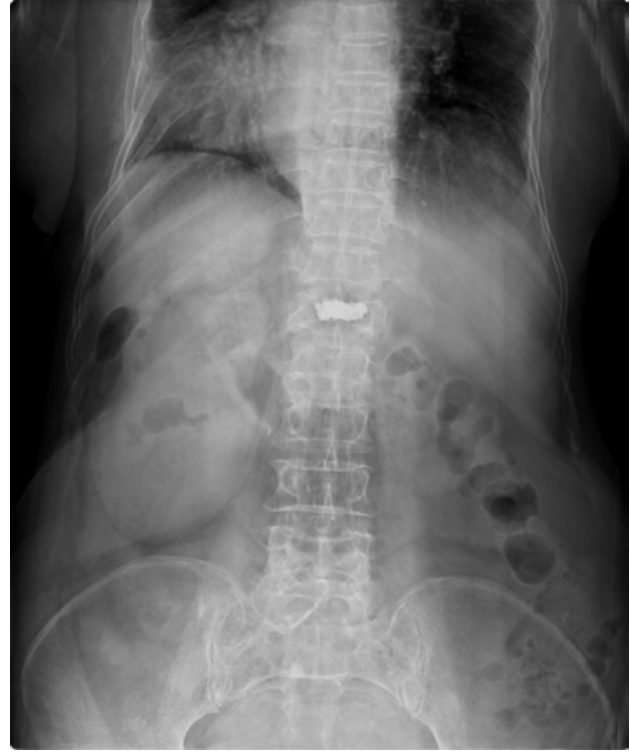

(A) Anteroposterior view

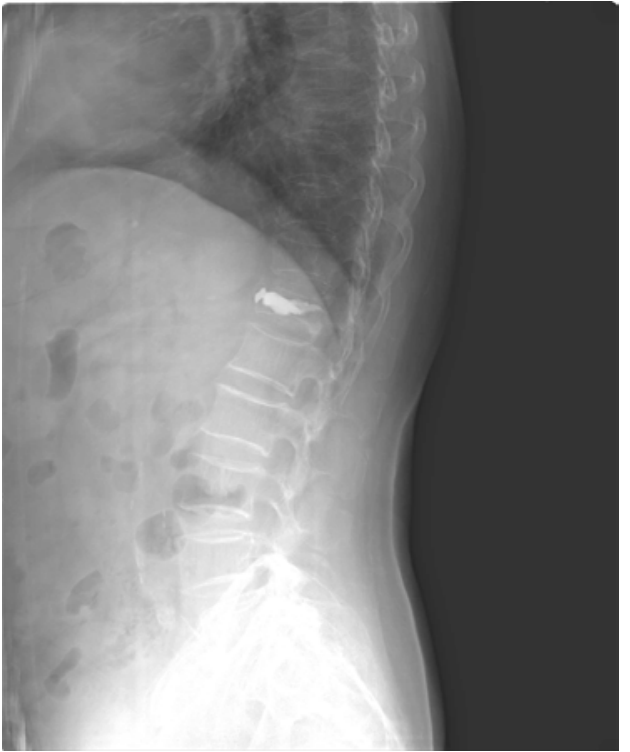

(B) Lateral view

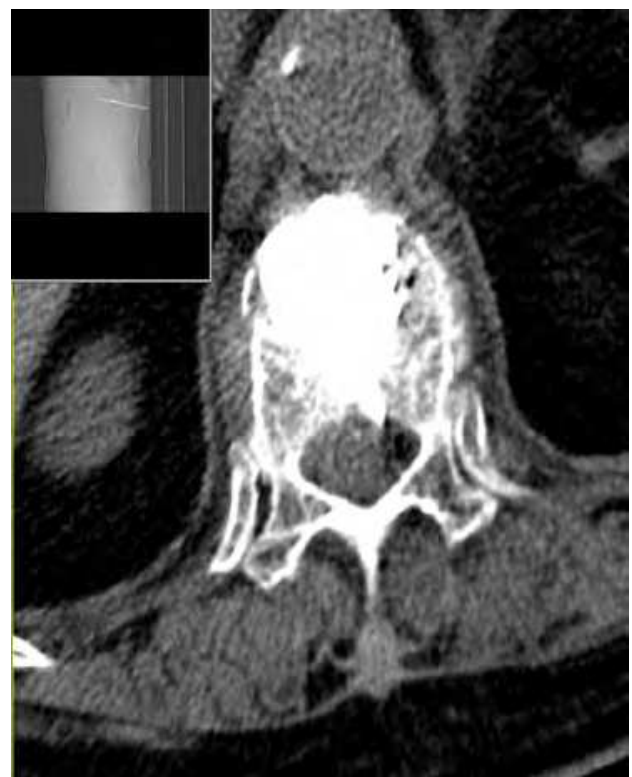

(C) Axial image of computed tomography

Fig. 3. Balloon Kyphoplasty using Unilateral approach 
There is no doubt that prevention of osteoporotic vertebral compression fractures is more important than surgical treatment. But in fractures not responding to prevention and conservative treatments, timely surgical intervention can afford to provide good reduction of fracture and correction of kyphosis and recovery of activity of daily living.

\section{References}

[1] Iqbal MM. Osteoporosis: Epidemilolgy, diagnosis, and treatment. South Med J 2000;93:218.

[2] Wasnich RD: Primer on the Metabolic Bone Diseases and Metabolism. 4th edition, 1999

[3] Riggs and Melton, New Eng J Med 1986;314:1676-86.

[4] Cooper C, Atkinson EJ, Jacobsen SJ et al. Population-based study of survival after osteoporotic fractures. Am J Epidemiol 1993;137:1001-1005.

[5] Truumees E, Hilibrand A, Vaccaro AR Percutaneous vertebral augmentation Spine J 2004;4:218-229.

[6] Zoarski GH, Snow P, Olan WJ et al. Percutaneous vertebroplasty for osteporotic compression fractures: Quantitiative prospective evaluation of long-term outcomes J Vasc Interv Radiol 2002;13:139-148.

[7] Riggs BL, Melton LJ III The worldwide problem of osteoporosis : Insights afforded by epidemiology Bone 1995;17:505S-511S.

[8] Cooper C, Atkinson EJ, O'Fallon WM et al Incidence of clinically diagnosed vertebral fractures: A population based study in Rochester, MN, 1985-1989 J Bone Miner Res 1992;7:221-227.

[9] Coumans JV, Reinhardt MK, Lieberman IH Kyphoplasty for vertebral compression fractures: 1-year clinical outcomes froma prospective study. J Neurosurg 2003;99:44-50.

[10] Lyles KW, Gold DT, Shipp KM et al Association of osteoporotic vertebral compression fractures with impaired functional status Am J Med 1993;94:595-601.

[11] Evans AJ, Jensen ME, Kip KE et al Vertebral compression fractures: Pain reduction and improvement in functional mobility after percutaneous polymethylmethacrylate vertebroplasty retrospective report of 245 cases Radiology 2003;226:366-372.

[12] Kado DM, Duong T, Stone KL et al Incident vertebral fractures and mortality on older women: A prospective study Osteoporosis IOnt 2003;14:589-594.

[13] Cauley JA et al., Osteoporos Int 2000;11:556-561.

[14] Browner WS et al., Arch Int Med 1996;156:1521-1525.

[15] Galibert P, Deramond H. Note préliminaire sur le traitement sed angiomes vertébraux par vertébroplastie acrylique percutanée. Neurochirurgie 1987;33:166-167.

[16] Eck JC, Hodges SD, Humphreys SC Vertebroplasty: A new treatment strategy for osteoporotic compression fractures. Am J Orthop 2002;31:123-128.

[17] Watts NB, Harris ST, Genant HK Treatment of painful osteoporotic vertebral fractures with percutaneous vertebroplasty or kyphoplasty Osteoporosis Int 2001;12:429-437.

[18] Garfin SR, Yuan HA, Reiley MA new technologies in spine: Kyphoplasty and vertebroplasty for the treatment of painful osteoporotic compression fractures. Spine 2001;26:1511-1515.

[19] Lieberman IH, Dudeney S, Reinhardt MK, Bell G Initial outcome and efficacy of kyphoplasty in the treatment of painful osteoporotic vertebral compression fractures. Spine 2001;26:1631-1638. 
[20] Ledlie J, Renfro M Balloon kyphoplasty: one-year outcomes in vertebral body height restoration, chronic pain and activity levels J Neurosurg 2003;26:1631-1638.

[21] Gaitanis IN, Hadjipavlou AG, Katonis PG, Tzermiadianosi MN, Pasku DS, Patwardhan AG Balloon kyphoplasty for the treatment of pathological vertebral compressive fractures. Eur Spine J 2005;14:250-260.

[22] Yoon ST, Quershi AA, Heller JG, Nordt JC 3 $3^{\text {rd }}$ Kyphoplasty for salvage of a failed vertebroplasty in osteoporotic vertebral compression fractures : case report and surgical technique. J Spinal Disord Tech;18(Suppl):S129-134.

[23] Boszczyk B, Bierschneider M, Hauck S, Beisse R, Potulski M, Jacsche H Transcostovertebral kyphoplasty of the mid and high thoracicspine Eur Spine J 2005;14:992-999.

[24] Lee YL, Yip KM The osteoporotic spine Clin Orthop Relat Res 1999;323:91-97.

[25] Chung HJ, Chung KJ, Yoon HS, Kwon IH Comparative study of blloon kyphoplasty with unilateral versus bilateral approach in osteoporotic vertebral compression fractures Int Orthop 2008;32:817-820. 


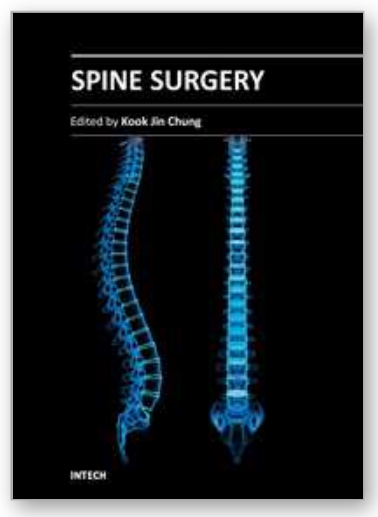

\author{
Spine Surgery \\ Edited by Dr. Kook Jin Chung
}

ISBN 978-953-51-0469-8

Hard cover, 148 pages

Publisher InTech

Published online 28, March, 2012

Published in print edition March, 2012

"Spine Surgery" is an authoritative and didactic textbook on the various fields of spine. It is written by many authors, internationally honorable experts to share their opinions with you. The chapters cover from anatomy of spine, spinal imaging technique, biology of spine, bone graft substitute, minimally invasive spinal surgery to even spinal deformity. It has many up to date results to help readers including university graduate students, medical instrumentation developers, and medical professionals including orthopaedic and neurosurgeons, rehabilitative professionals. The readers are provided with precious information and valuable guide in your daily practice.

\title{
How to reference
}

In order to correctly reference this scholarly work, feel free to copy and paste the following:

Kook Jin Chung (2012). Osteoporotic Verterbal Compression Fractures, Spine Surgery, Dr. Kook Jin Chung (Ed.), ISBN: 978-953-51-0469-8, InTech, Available from: http://www.intechopen.com/books/spinesurgery/osteoporotic-verterbal-compression-fractures

\section{INTECH}

open science | open minds

\section{InTech Europe}

University Campus STeP Ri

Slavka Krautzeka 83/A

51000 Rijeka, Croatia

Phone: +385 (51) 770447

Fax: +385 (51) 686166

www.intechopen.com

\section{InTech China}

Unit 405, Office Block, Hotel Equatorial Shanghai

No.65, Yan An Road (West), Shanghai, 200040, China

中国上海市延安西路65号上海国际贵都大饭店办公楼 405 单元

Phone: +86-21-62489820

Fax: +86-21-62489821 
(C) 2012 The Author(s). Licensee IntechOpen. This is an open access article distributed under the terms of the Creative Commons Attribution 3.0 License, which permits unrestricted use, distribution, and reproduction in any medium, provided the original work is properly cited. 